\title{
Excitotoxic Brain Injury Suppresses Striatal High-Affinity Glutamate Uptake in Perinatal Rats
}

\author{
Bernadine Hu, ${ }^{*}$ John W. McDonald, †Michael V. Johnston, and Faye S. Silverstein \\ Departments of Pediatrics and Neurology and ${ }^{*}$ The Neuroscience and Medical Scientist Training Program, \\ University of Michigan, Ann Arbor, Michigan; and †Departments of Neurology and Pediatrics, \\ Johns Hopkins University and The Kennedy Research Institute, Baltimore, Maryland, U.S.A.
}

\begin{abstract}
In immature rodent brain, the glutamate receptor agonist $N$-methyl-D-aspartate (NMDA) is a potent neurotoxin. In postnatal day (PND)-7 rats, intrastriatal injection of $25 \mathrm{nmol}$ of NMDA results in extensive ipsilateral forebrain injury. In this study, we examined alterations in high-affinity [ $\left.{ }^{3} \mathrm{H}\right]$ glutamate uptake (HAGU) in NMDA-lesioned striatum. HAGU was assayed in synaptosomes, prepared from lesioned striatum, the corresponding contralateral striatum, or unlesioned controls. Twenty-four hours after NMDA injection ( $25 \mathrm{nmol})$, HAGU declined $44 \pm 8 \%$ in lesioned tissue, compared with the contralateral striatum (mean $\pm \mathrm{SEM}, \mathrm{n}=6$ assays, $p<0.006$, paired $t$ test). Doses of 5-25 nmol of NMDA resulted in increasing suppression of HAGU $(5 \mathrm{nmol}, \mathrm{n}=3$; $12.5 \mathrm{nmol}, \mathrm{n}=3$; and $25 \mathrm{nmol}, \mathrm{n}=5$ assays; $p<0.01$, regression analysis). The temporal evolution of HAGU suppression was biphasic. There was an early transient suppression of HAGU $(-28 \pm 4 \%$ at $1 \mathrm{~h} ; p<0.03$, analysis of variance, comparing changes at $0.5,1,2$, and $3 \mathrm{~h}$ after lesioning); 1 or 5 days postinjury there was sustained loss of
\end{abstract}

HAGU (at 5 days, $-56 \pm 11 \%, \mathrm{n}=3, p<0.03$, paired $t$ test, lesioned versus contralateral striata). Treatment with the noncompetitive NMDA antagonist MK-801 (1 mg $/ \mathrm{kg}$ i.p.) attenuated both the early and subsequent irreversible suppression of HAGU ( $1 \mathrm{~h}$ postlesion $-28 \pm 4 \%, \mathrm{n}=6$ assays versus $-12.6 \pm 5 \%$ with MK-801, $\mathrm{n}=4, p=0.005 ; 24 \mathrm{~h}$ postlesion, $-44 \pm 8 \%, n=5$, versus $+2.4 \pm 6 \%, n=3$ with MK-801, $p=0.01$, Wilcoxon ranked sum tests). In immature brain excitotoxic lesions produce an acute reversible suppression of HAGU, and a delayed long-lasting reduction in HAGU secondary to brain injury. These data suggest that accumulation of endogenous glutamate, as a consequence of the acute disruption of HAGU, could contribute to the pathogenesis of excitotoxic neuronal injury. Key Words: Perinatal- $N$-Methyl-D-aspartate-Glutamate-StriatumUptake-Injury. Hu B. et al. Excitotoxic brain injury suppresses striatal high-affinity glutamate uptake in perinatal rats. J. Neurochem. 56, 933-937 (1991).
The selective glutamate receptor agonist $N$-methyl$D$-aspartate (NMDA) is a potent neurotoxin in the developing brain (McDonald et al., 1988). Unilateral intrastriatal injection of NMDA in postnatal day (PND)7 rats produces an ipsilateral forebrain lesion; doses of 5-25 nmol of NMDA result in progressive reductions in tissue mass, regional cross-sectional areas, and choline acetyltransferase (ChAT) activity (McDonald et al., 1989a). Systemic administration of the noncompetitive NMDA antagonist MK-801 prevents NMDAinduced tissue damage (Foster et al., 1987, 1988; McDonald et al., 1989b).

Excitatory amino acid (EAA) neurotransmitters are rapidly removed from the synaptic cleft by reuptake into glutamatergic nerve terminals and glia (Fonnum, 1984). Suppression of reuptake could thus result in increased or prolonged synaptic accumulation of released transmitter. The role of endogenous EAA in the pathogenesis of NMDA-induced injury is uncertain. Previously, in a model of perinatal hypoxic-ischemic brain injury, we found that there was a marked, reversible suppression of high-affinity $\left[{ }^{3} \mathrm{H}\right]$ glutamate uptake (HAGU) in synaptosomes prepared from acutely lesioned striatum (Silverstein et al., 1986). Reductions in HAGU activity appeared to precede the onset of irreversible neuronal damage and our data suggested that this functional disruption could represent a pathophysiologic mechanism whereby EAA could ac-
Received June 25, 1990; revised manuscript received August 27, 1990; accepted September 5, 1990.

Address correspondence and reprint requests to Dr. F. S. Silverstein at Room 6028, Kresge II, University of Michigan, Ann Arbor, MI 48109-0570, U.S.A.
Abbreviations used: ANOVA, analysis of variance; BSA, bovine serum albumin; ChAT, choline acetyltransferase; EAA, excitatory amino acids; HAGU, high-affinity glutamate uptake; NMDA, $N$ methyl-D-aspartate; PND, postnatal day. 
cumulate at the synaptic cleft and contribute to the evolution of ischemic brain injury.

Synaptosomal HAGU assays enable measurement

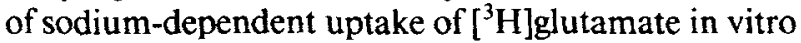
and provide a method for assessment of the functional integrity of striatal presynaptic glutamatergic nerve terminals (Bennett et al., 1973). In PND-7 rats, striatal HAGU activity is considerably lower than in adult brain, presumably reflecting immaturity of striatal glutamatergic innervation (Campochiaro and Coyle, 1978). In this study, we examined the impact of intrastriatal NMDA injections on striatal HAGU to determine if excitotoxic lesions disrupted HAGU in immature rat brain. We assessed the dose-response characteristics and time course of NMDA-induced suppression of striatal HAGU, and the extent to which treatment with the noncompetitive NMDA antagonist MK-801 (Wong et al., 1986) preserved HAGU. Based on the hypothesis that increased concentrations of free fatty acids could suppress HAGU activity acutely (Rhoads et al., 1982; Chan et al., 1983) and on the observation that incubation of synaptosomes from hypoxic-ischemic striatum with albumin restored HAGU activity (Silverstein et al., 1986), we also determined the effects of albumin on HAGU in NMDAlesioned striatum.

\section{MATERIALS AND METHODS}

\section{Animal preparation}

PND-7 Sprague-Dawley rats were anesthetized with ether for $3 \mathrm{~min}$. Stereotaxically guided intrastriatal NMDA injections were performed as previously described by McDonald et al. (1989a). After a midline scalp incision was made to expose the calvarium, the injection site was identified using bregma as a landmark (coordinates: AP $2.0 \mathrm{~mm}, \mathrm{~L} 2.5 \mathrm{~mm}$, depth $4 \mathrm{~mm}$.). A Kopf small animal stereotaxic apparatus was used to guide injections, which were done with a 26gauge Hamilton syringe. NMDA (5-25 $\mathrm{nmol}$ ) was dissolved in $0.01 M$ Tris, pH 7.4, and injected over 2 min (volume, $0.5 \mu 1)$. The scalp was sutured, and rats were allowed to recover under a warming lamp. When MK-801 was administered, $1 \mathrm{mg} / \mathrm{kg}$ was injected intraperitoneally (volume, 0.1 $\mathrm{ml}) 15 \mathrm{~min}$ after the NMDA injection, and littermate NMDAlesioned controls were injected with equal volumes of saline. Animals were killed by decapitation, and striata were quickly dissected on ice.

Eighteen experiments were done (mean number of animals per experiment $=11$ ). The surgical protocol was approved by the University of Michigan Committee on Care and Use of Animals.

\section{HAGU assay}

Sodium-dependent HAGU was measured according to the methods of Bennett et al. (1973). Each experiment included striatal samples from the side of lesioning, the contralateral hemisphere, and unlesioned or saline-injected littermate controls. For each synaptosome preparation, tissue from two corresponding striata were pooled; final values were averaged from triplicate synaptosome preparations assayed concurrently.
Tissue and reagents were kept on ice. Tissue was homogenized 1:20 in isotonic sucrose $(0.32 M)$, the $\mathrm{P} 2$ fraction was isolated by repeated centrifugation and resuspended in 200 $\mu 1$ of sucrose. Four 25- $\mu$ l aliquots of the synaptosome pellet (duplicate samples and blanks) were incubated for $10 \mathrm{~min}$ at $37^{\circ} \mathrm{C}$ in $950 \mu 1$ of Krebs-Ringer phosphate buffer, $\mathrm{pH} 7.4$, with $14 \mathrm{mM}$ glucose; in the buffer for blanks, choline chloride substituted for $\mathrm{NaCl}$. In experiments to test albumin's effects on HAGU, $1 \mathrm{mg} / \mathrm{ml}$ of bovine serum albumin (BSA, alcoholprecipitated, 95-99\% pure, Sigma) was added to the incubation buffer. Then, $20 \mu l$ of $\left[{ }^{3} \mathrm{H}\right]$ glutamate $(1 \mathrm{mCi} / \mathrm{ml}$, Amersham, Arlington Heights, IL, U.S.A.) was added $(20 \mu \mathrm{l}$ $\left[{ }^{3} \mathrm{H}\right.$ ]glutamate in $1 \mathrm{ml}$ of $5 \mu M$ glutamate); after a 4-min incubation, HAGU was stopped by addition of excess cold sodium-deficient buffer, followed by centrifugation at 20,000 $g$ for $15 \mathrm{~min}$. The pellet was dissolved in tissue solubilizer and accumulated radioactivity was counted. Counts in blanks were subtracted from total counts. The protein content in an aliquot of each synaptosome preparation was assayed (Bradford, 1976), and specific uptake per microgram of protein was calculated. In these experiments $(n=18)$, HAGU activity in controls (mean $\pm \mathrm{SEM}$ ) was $8.8 \pm 1 \mathrm{pmol} / \mathrm{min} /$ $\mathrm{mg}$ of protein.

\section{Experimental protocols}

After preliminary data demonstrated a marked NMDAinduced reduction in striatal HAGU, four groups of experiments were done to characterize this response.

To determine the relationship between the amount of NMDA injected and the extent of HAGU suppression, striatal HAGU was compared in synaptosomes derived from animals that received right intrastriatal injections of $5,12.5$, or 25 $\mathrm{nmol}$ NMDA and were killed $24 \mathrm{~h}$ later $(\mathrm{n}=3,3$, and 5 assays, respectively). Higher NMDA doses were not tested because doses above $25 \mathrm{nmol}$ result in increased mortality and bihemispheric tissue damage; $5 \mathrm{nmol}$ is the lowest dose that reliably elicits histologic damage.

To assess the temporal evolution of NMDA-induced HAGU suppression, side-side differences in striatal HAGU were compared in tissue from animals killed at $0.5,1,2$, and $3 \mathrm{~h}$ after NMDA lesioning ( $25 \mathrm{nmol}, \mathrm{n}=1,6,3$, and 3 assays, respectively), and in animals killed $24 \mathrm{~h}$ or 5 days later ( $=5$ and 3 assays, respectively).

In one experiment, albumin-induced stimulation of HAGU was assessed. Saline- and NMDA-injected animals were killed $1 \mathrm{~h}$ postlesioning ( $\mathrm{n}=4$ animals per group), synaptosomes were prepared from the injected and contralateral striata of each group, and HAGU was compared in aliquots from each synaptosome preparation incubated with or without added BSA $(1 \mathrm{mg} / \mathrm{ml})$.

The neuroprotective actions of MK-801 were evaluated at two time intervals, 1 and $24 \mathrm{~h}$ postlesioning. In seven experiments, animals received intrastriatal injections of $25 \mathrm{nmol}$ NMDA, half received $1 \mathrm{mg} / \mathrm{kg} \mathrm{MK}-80115 \mathrm{~min}$ later, and the others received an equal volume of saline. Animals were killed 1 ( $n=4$ assays) or $24 \mathrm{~h}(\mathrm{n}=3)$ later. For the data analysis, values from additional experiments in which animals had received the same dose of NMDA and were sacrificed at the same time interval were also included.

\section{Data analysis}

Because there was interassay variation in absolute values for HAGU, to incorporate results from multiple experiments, HAGU values in lesioned animals were expressed as per- 
centage of HAGU in untreated littermate controls assayed in the same experiment. For these data $n$ indicates number of independent experiments; values are means \pm SEM of triplicate assays, calculated as $\mathrm{dpm} / \mathrm{min} / \mu \mathrm{g}$ protein and expressed as a percentage of HAGU in controls.

In samples from lesioned animals, percent change was calculated as: [(percentage of HAGU activity in contralateral striatum) - (percentage of HAGU activity in injected striatum)]/(percentage of HAGU activity in contralateral striatum); percent change values for the dose-response analysis were compared with regression analysis; values for the timecourse analysis were compared with analysis of variance (ANOVA), and percent change values in untreated and MK801-treated animals were compared with Wilcoxon rank-sum tests.

\section{RESULTS}

Striatal HAGU was compared in synaptosomes from PND-7 animals that received right intrastriatal injections of $5,12.5$, or $25 \mathrm{nmol}$ of NMDA and were killed $24 \mathrm{~h}$ later (Fig. 1); side-side differences at each dose were compared by regression analysis $(p<0.01)$. In tissue from the contralateral striatum HAGU did not change, whereas in tissue derived from the injected striatum there was a progressive, dose-related reduction in HAGU; at the highest dose tested HAGU declined $44 \pm 8 \%$ (mean \pm SEM).

The time-course analysis (Fig. 2) revealed a biphasic suppression of HAGU. Comparison of side-side differences in animals killed at $0.5,1,2$, and $3 \mathrm{~h}$ after NMDA lesioning demonstrated a transient, reversible suppression of HAGU; HAGU was reduced at the earliest time intervals but activity was restored at $2-3 \mathrm{~h}$ (ANOVA, $p<0.03$ ). Subsequently, in animals killed $24 \mathrm{~h}$ or 5 days later, a marked reduction in HAGU in lesioned tissue persisted (at $24 \mathrm{~h}:-44 \pm 8 \%, p<0.006$ paired $t$ test comparing contralateral and lesioned striata, $\mathrm{n}=6$ assays; at $120 \mathrm{~h}, \mathrm{n}=3,-56 \pm 11 \%, p$ $<0.03$ ). In controls that received unilateral intrastriatal

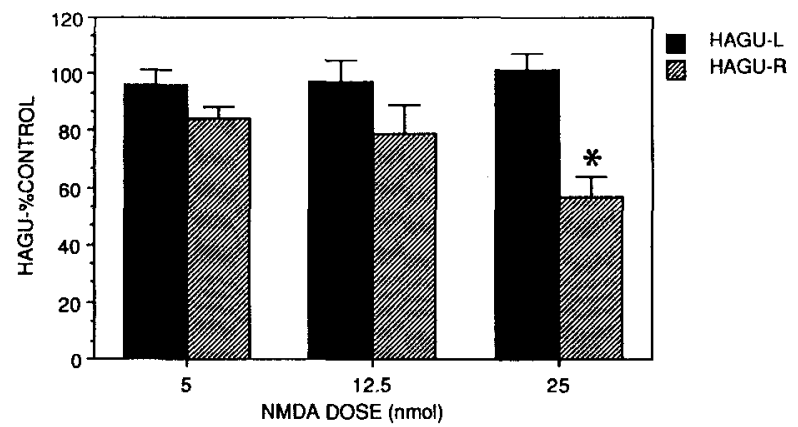

FIG. 1. Striatal HAGU was compared in synaptosomes from PND7 animals that received right intrastriatal injections of $5,12.5$, or $25 \mathrm{nmol}$ of NMDA and were killed $24 \mathrm{~h}$ later $(\mathrm{n}=3,3$, and 5 assays, respectively). In tissue from the hemisphere contralateral to the lesion, HAGU-L values, expressed as percent \pm SEM of activity in untreated controls, did not change, whereas in tissue derived from the injected striatum (HAGU-R) there was a progressive, dose-related reduction in HAGU. Side-side differences in each group were compared by regression analysis; ${ }^{*} p<0.01$.

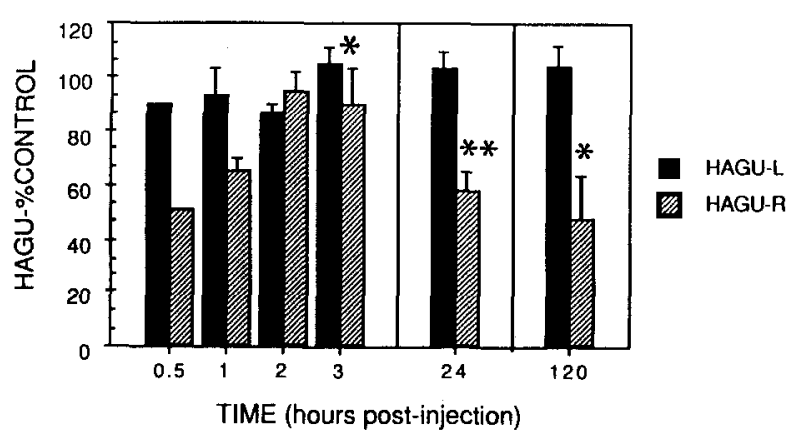

FIG. 2. Striatal HAGU was compared in synaptosomes from animals that received right intrastriatal injections of $25 \mathrm{nmol}$ of NMDA and were killed $1 \mathrm{~h}$ to 5 days later. In tissue from the hemisphere contralateral to the lesion, HAGU-L values, expressed as percent \pm SEM of activity in samples from untreated controls assayed concurrently, did not change. In tissue from the injected striatum (HAGU-R) there was an initial transient reduction in HAGU, followed by a subsequent apparently irreversible loss of HAGU activity. Sideside differences in animals killed at $0.5,1,2$, and $3 \mathrm{~h}$ after NMDA lesioning were compared by ANOVA $\left({ }^{*} p<0.03\right)$. HAGU in tissue derived from the contralateral and lesioned striata of animals killed $24 \mathrm{~h}(\mathrm{n}=6$ assays) or $120 \mathrm{~h}(\mathrm{n}=3)$ after lesioning were compared by paired, two-tailed $t$ tests $\left({ }^{*} p<0.03 ;{ }^{* *} p<0.006\right.$ ).

injections of saline and were killed 1 or $24 \mathrm{~h}$ or 5 days later, there were no side-side differences in HAGU (data not shown). In a single experiment, in vitro incubation of synaptosomes from untreated animals with NMDA (10-100 $\mu M$, for 2 min before addition of $\left[{ }^{3} \mathrm{H}\right]$ glutamate) suppressed HAGU by $20-26 \%$.

Addition of albumin to the incubation buffer stimulated HAGU in all tissue samples $(p<0.001$, paired $t$ test); values increased by $39-56 \%$ in unlesioned tissue and by $89 \%$ in acutely lesioned striatum (Table 1).

In NMDA-lesioned animals, administration of $1 \mathrm{mg} /$ $\mathrm{kg}$ of MK-801 attenuated NMDA-induced suppression of striatal HAGU (Fig. 3). In animals killed 1 or $24 \mathrm{~h}$

TABLE 1. Effect of albumin on sodium-dependent $l^{3}$ H]glutamate uptake

\begin{tabular}{|c|c|c|c|}
\hline \multirow[b]{2}{*}{ Source of tissue } & \multicolumn{2}{|c|}{$\begin{array}{l}\mathrm{HAGU}(\mathrm{pmol} / \mathrm{min} / \\
\mathrm{mg} \text { of protein) }\end{array}$} & \multirow[b]{2}{*}{ Percent increas } \\
\hline & $-\mathrm{BSA}$ & $+\mathrm{BSA}^{a}$ & \\
\hline \multicolumn{4}{|l|}{ Saline-injected } \\
\hline Contralateral & 9.86 & 13.72 & +39.1 \\
\hline Ipsilateral & 8.49 & 13.28 & +56.5 \\
\hline \multicolumn{4}{|l|}{ NMDA-injected } \\
\hline Contralateral & 8.94 & 13.30 & +48.8 \\
\hline Ipsilateral & 5.91 & 11.17 & +88.9 \\
\hline
\end{tabular}

The extent of stimulation of HAGU elicited by addition of $1 \mathrm{mg} /$ $\mathrm{ml}$ of BSA to the incubation buffer was compared in synaptosome preparations derived from four saline-injected and four NMDA (25 nmol)-injected PND-7 rats. Animals were killed $1 \mathrm{~h}$ postinjection. Two striata were pooled per synaptosome preparation, and $\left[{ }^{3} \mathrm{H}\right]$ HAGU activity was assayed concurrently in -BSA and + BSA incubations buffers, as described in Materials and Methods. ${ }^{a} p$ $<0.001$, paired $t$ test, comparing -BSA and +BSA. 


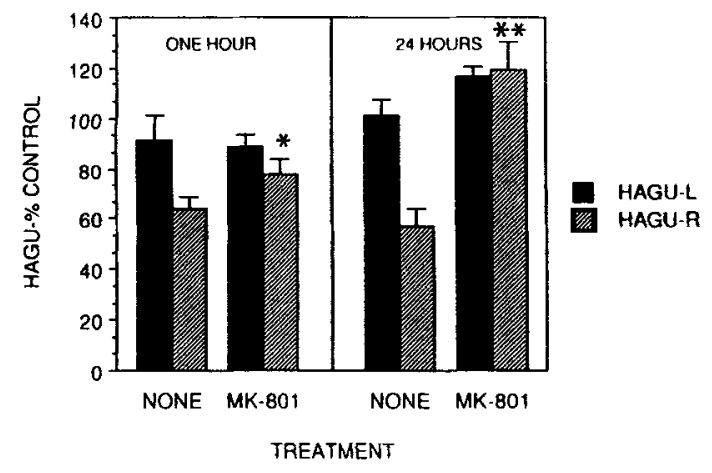

FIG. 3. Effects of MK-801 administration on the magnitude of NMDA-induced suppression of striatal HAGU were assessed at two time intervals, $1 \mathrm{~h}$ and $24 \mathrm{~h}$ postlesioning. In seven experiments, PND-7 rats received right intrastriatal injections of $25 \mathrm{nmol}$ of NMDA and half received $1 \mathrm{mg} / \mathrm{kg}$ MK-801 by intraperitoneal injection 15 $\mathrm{min}$ later and the others received an equal volume of saline. Animals were killed $1 \mathrm{~h}$ ( $n=4$ assays) or $24 \mathrm{~h}(\mathrm{n}=3$ ) later. Values from additional experiments in which animals had received the same dose of NMDA and were killed at the same time intervals were also included in the data analysis. Side-side differences in HAGU (expressed as percent \pm SEM of control values) were compared at each time interval in untreated and MK-801-treated animals with Wilcoxon rank-sum tests (number of assays at $1 \mathrm{~h}$ : no treatment, $\mathrm{n}=6$, MK-801, $\mathrm{n}=4$; at $24 \mathrm{~h}$ : no treatment, $\mathrm{n}=5$, MK-801, $\mathrm{n}$ $=3) .{ }^{*} p=0.005 ;{ }^{* *} p=0.01$

after lesioning HAGU was relatively preserved in the lesioned striatum of MK-801-treated animals: at $1 \mathrm{~h}$, $-28 \pm 4 \%$ in untreated animals versus $-12.6 \pm 5 \%$ in MK-801-treated group, $p=0.005$; at $24 \mathrm{~h},-44 \pm 8 \%$ versus $+2.4 \pm 6 \%$ after MK-801 treatment, $p=0.01$, Wilcoxon rank-sum tests.

\section{DISCUSSION}

These data demonstrate that in PND-7 rats unilateral intrastriatal injections of NMDA resulted in dose-dependent suppression of HAGU. There was an early transient reduction in functional activity and subsequent irreversible loss of HAGU; treatment with MK801 blocked these effects.

Although the methods used did not allow repeated measures in a single animal, the time-course data, based on values from animals killed at sequential time intervals after lesioning, indicated that suppression of HAGU was biphasic. Of interest, the acute, transient suppression of HAGU in NMDA-lesioned striatum paralleled the reversible loss of HAGU activity observed during the evolution of hypoxic-ischemic brain injury in PND-7 rats (Silverstein et al., 1986). Factors that could contribute to this early loss of functional activity include depletion of metabolic substrates required to maintain membrane integrity, sustained membrane depolarization, or accumulation of toxic metabolites. For example, NMDA receptor activation stimulates arachidonic acid release (Dumuis et al., 1988). Arachidonate inhibits HAGU in vitro (Rhoads et al., 1982; Chan et al., 1983; Barbour et al., 1989) and may act similarly in vivo; the observed stimulatory effects of albumin on HAGU may well be attributable to chelation of arachidonate and other free fatty acids (Rhoads et al., 1982). It is surprising that preincubation of synaptosomes in a glucose-containing, physiologic buffer did not abolish any NMDA-induced metabolic derangements or membrane potential changes that contributed to the acute suppression of HAGU observed.

Irreversible loss of HAGU most likely reflects structural damage to specific glutamate recognition or carrier sites on presynaptic nerve terminals or on glia. Damage to cortico-striatal afferent neurons or to glutamatergic nerve terminals within striatum could contribute to loss of HAGU activity. Intrastriatal NMDA injections result in injury to adjacent, overlying cortex (McDonald et al., 1988) and the reductions in striatal HAGU could, in part, result from damage to corticostriatal afferent neurons. However, based on previous studies of the patterns of neurotoxicity of the glutamate analogue kainate, relative sparing of presynaptic glutamatergic nerve terminals might have been expected in NMDA-lesioned animals (Coyle and Schwarcz, 1976; Coyle et al., 1978; Vincent and McGeer, 1980). After intrastriatal injection of kainic acid $(5 \mathrm{nmol})$ in adult brain, HAGU activity was unchanged whereas ChAT activity, a marker of intrinsic striatal cholinergic neurons, decreased by $70 \%$ (Vincent and McGeer, 1980). Previously, we found a direct linear relationship between the dose of NMDA injected intrastriatally and the extent of tissue damage (over the range $5-25 \mathrm{nmol}$ ) in PND-7 rats (McDonald et al., 1989a). ChAT activity, declined to a similar extent in NMDA-lesioned striatum. In animals killed 5 days after intrastriatal injection of NMDA ( $25 \mathrm{nmol})$, the magnitude of reductions in striatal cross-sectional area, ChAT activity, and HAGU were similar and indicated no selective sparing of presynaptic nerve terminals.

NMDA neurotoxicity is presumably mediated directly by receptor activation (Rothman and Olney, 1987). Both competitive and noncompetitive NMDA antagonists block NMDA-induced neuronal damage (Foster et al., 1988; McDonald et al., 1989a). The ability of MK-801 treatment to limit NMDA-induced reductions in HAGU suggested that loss of uptake activity was a consequence of NMDA receptor activation. Yet, in striatum, NMDA receptors are concentrated postsynaptically (Greenamyre and Young, 1989) whereas glutamate uptake sites are localized presynaptically (Vincent and McGeer, 1980). Thus, NMDAinduced damage to presynaptic glutamatergic terminals is likely to be mediated indirectly, and result from factors such as energy depletion, accumulation of toxic metabolites, or damage to protective inhibitory neurons.

Synaptosomal HAGU could also, in part, reflect glial rather than neuronal glutamate uptake activity. However, 5 days after NMDA lesioning there is prominent gliosis (Silverstein, unpublished observation). If the glial contribution to HAGU were significant, increased ac- 
tivity, rather than the pronounced decrease observed, would be expected.

Several lines of investigation indicate that NMDAinduced neuronal damage progresses for hours after initial exposure (Rothman et al., 1987; Foster et al., 1988; McDonald et al., 1990). In this experimental model, MK-801 administration up to $2 \mathrm{~h}$ after intrastriatal NMDA lesioning prevents $>90 \%$ of tissue damage (McDonald et al., 1990). The role of endogenous EAA neurotransmitters in the pathogenesis of NMDA-induced damage in vivo is uncertain. Inhibition of HAGU could contribute to accumulation of toxic concentrations of EAA at the synapse (Kohler and Schwarcz, 1981). Our data suggest that in the immature brain presynaptic mechanisms such as suppression of HAGU may play an important role in the evolution of excitotoxic neuronal injury.

Acknowledgment: This work was supported by PHS Grants NS26142 and NS01171 (F.S.S.), the University of Michigan Biomedical Research Program (B.H.), and an MSTP fellowship (J.W.M.). MK-801 was provided by Merck Sharp and Dohme Laboratories.

\section{REFERENCES}

Barbour B., Szatkowki M., Ingleden N., and Attwell T. (1989) Arachidonic acid induced a prolonged inhibition of glutamate uptake into glial cells. Nature 342, 918-920.

Bennett J. P., Logan W. J., and Snyder S. H. (1973) Amino acids as central nervous system transmitters: the influence of ions, amino acid analogues, and ontogeny on transport systems for L-glutamic and L-aspartic acids and glycine into central nervous synaptosomes of the rat. $J$. Neurochem. 21, 1533-1550.

Bradford M. (1976) A rapid, sensitive method for the quantitation of microgram quantities of protein utilizing the principle of protein-dye binding. Anal. Biochem. 72, 248-253.

Chan P. H., Kerlan R. A., and Fishman R. A. (1983) Reductions of GABA and glutamate uptake and $\mathrm{Na}^{+}+\mathrm{K}^{+}$-ATPase activity in brain slices and synaptosomes by arachidonic acid. J. Neurochem. 40, 309-316.

Campochiaro P. and Coyle J. (1978) Ontogenetic development of kainate neurotoxicity: correlates with glutamatergic innervation. Proc. Natl. Acad. Sci. USA 75, 2025-2029.

Coyle J. T. and Schwarcz R. (1976) Lesion of striatal neurons with kainic acid provides a model for Huntington's chorea. Nature 263, 244-246.

Coyle J. T., Molliver M. E., and Kuhar M. J. (1978) In situ injection of kainic acid: a new method for selectively lesioning neuronal cell bodies while sparing axons of passage. J. Comp. Neurol. 180 , 301-324.
Dumuis A., Sebben M., Haynes L., Pin J. P., and Bockaert J. (1988) NMDA receptors activate the arachidonic acid cascade system in striatal neurons. Nature 336, 68-70.

Fonnum F. (1984) Glutamate: a neurotransmitter in mammalian brain, $J$. Neurochem 42, 1-11.

Foster A. C., Gill R., Kemp J. A., and Woodruff G. (1987) Systemic administration of MK- 801 prevents $N$-methyl-D-aspartate-induced neuronal degeneration in rat brain. Neurosci. Lett. 76, 307-311.

Foster A. C., Gill R., and Woodruff G. N. (1988) Neuroprotective effects of MK-801 in vivo: selectivity and evidence for delayed degeneration mediated by NMDA receptor activation. $J$. Neurosci. 8, 4745-4754.

Greenamyre J. T. and Young A. B. (1989) Synaptic localization of striatal NMDA, quisqualate, and kainate receptors. Neurosci. Lett. 101, 1133-1137.

Kohler C. and Schwarcz R. (1981) Monosodium glutamate: increased neurotoxicity after removal of neuronal reuptake sites. Brain Res. 211, 485-491.

McDonald J. W., Silverstein F. S., and Johnston M. V. (1988) Neurotoxicity of $N$-methyl-D-aspartate is markedly enhanced in the developing rat central nervous system. Brain Res. 459, 200203.

McDonald J. W., Roeser N. F., Silverstein F. S., and Johnston M. V. (1989a) Quantitative assessment of neuroprotection against NMDA-induced brain injury. Exp. Neurol. 106, 289296.

McDonald J. W., Silverstein F. S., and Johnston M. V. (1989b) Neuroprotective effects of MK-801, TCP, PCP and CPP against $N$ methyl-D-aspartate induced neurotoxicity in an in vivo perinatal rat model. Brain Res. 490, 33-40.

McDonald J. W., Silverstein F. S., Cardona D., Hudson C., Chen R., and Johnston M. V. (1990) Systemic administration of MK801 protects against $N$-methyl-D-aspartate and quisqualate mediated neurotoxicity in perinatal rats. Neuroscience 36, 589600 .

Rhoads E. G., Kaplan M. A., Peterson N. A., and Ragupathy E. (1982) Effects of free fatty acids on synaptosomal amino acid uptake systems. J. Neurochem. 38, 1255-1260.

Rothman S. M. and Olney J. W. (1987) Excitotoxicity and the NMDA receptor. Trends. Neurosci. 10, 299-302.

Rothman S. M., Thurston J. H., and Hanhart R. E. (1987) Delayed neurotoxicity of excitatory amino acids in vitro. Neuroscience 22, 471-480.

Silverstein F. S., Buchanan K., and Johnston M. V. (1986) Perinatal hypoxia-ischemia disrupts striatal high affinity ${ }^{3} \mathrm{H}$-glutamate uptake into synaptosomes. $J$. Neurochem. 47, 1615-1619.

Vincent S. R. and McGeer E. G. (1980) A comparison of sodiumdependent glutamate binding with high affinity glutamate uptake in rat striatum. Brain Res. 184, 99-108.

Wong E. H. F., Kemp J. A., Priestly T., Knight A. R., Woodruff G. N., and Iversen L. L. (1986) The anticonvulsant MK-801 is a potent $N$-methyl-D-aspartate antagonist. Proc. Natl. Acad. Sci. USA 83, 7102-7108. 